\title{
sciendo
}

\section{Relationships Between Isokinetic Shoulder Evaluation and Fitness Characteristics of Elite French Female Water-Polo Players}

\author{
by \\ Nicolas Olivier ${ }^{1}$, Frédéric N. Daussin ${ }^{1}$
}

Swimming and throwing are involved in water-polo player performance. These movements have a common biomechanical basis in the use of the internal shoulder rotation and adductor muscles. The aim of the study was to evaluate the relationship between shoulder isokinetic evaluation and throwing velocity as well as swimming performance in female water-polo players. Fifteen high level water-polo players completed two isokinetic shoulder evaluations to determine peak torque of shoulder rotators of the dominant shoulder (concentric and eccentric movements at an angular velocity of $60^{\circ} \cdot \mathrm{s}-1$ and concentric movements at an angular velocity of $240^{\circ} \cdot \mathrm{s}-1$ ) and shoulder extensors of both arms (concentric movements at an angular velocity of $60^{\circ} \cdot s-1$ and $240^{\circ} \cdot s-1$ ). Throwing velocity was measured using a radar gun placed $5 \mathrm{~m}$ behind the goal post. Front crawl swimming velocity was determined at $25 \mathrm{~m}$, $100 \mathrm{~m}$ and $400 \mathrm{~m}$ distances. Concentric peak torque at $60^{\circ} \cdot \mathrm{s}-1$ and $240^{\circ} \cdot \mathrm{s}-1$ of internal rotators and eccentric peak torque at $60^{\circ} \cdot \mathrm{s}-1$ of external rotators were predictors of throwing velocity. The best model to explain the relationship between isokinetic evaluations and throwing velocity was obtained with concentric IR peak torque at $60^{\circ} \cdot s-1$ and eccentric ER peak torque at $60^{\circ} \cdot \mathrm{s}-1(r 2=0.52, p=0.012)$. Relative total work done and peak torque of shoulder extensors were predictors of $25 \mathrm{~m}$ swimming velocity. Shoulder isokinetic evaluations correlate significantly with swimming performance and throwing velocity of female water-polo players. The results may help coaches to develop new strategies such as eccentric dry land training programs to increase both shoulder external rotators strength and throwing velocity.

Key words: internal rotators, external rotators, swimming, throwing velocity, female athletes.

\section{Introduction}

Water-polo is an intermittent and highintensity team sport (Smith, 1998). The objective of this discipline is to score more goals than the opposite team and success requires a combination of technique, a high level of physical fitness and tactical skills (Botonis et al., 2016; Ordóñez et al., 2016; Tucher et al., 2015). Consequently, the basic characteristics of elite water-polo players are the ability to throw the ball with a high velocity and to swim at high speed (Alcaraz et al., 2011;
Martínez et al., 2015; Tan et al., 2009b; Vila et al., 2011; Zinner et al., 2015).

Throwing is considered as one of the most important aspects of performance (Alcaraz et al., 2011; Martínez et al., 2015). Accuracy and throwing speed are two crucial factors involved in throwing efficacy (Alcaraz et al., 2011). The faster and more precise the throw, the more difficult it is for the defense and goalkeeper to intercept the ball. $90 \%$ of throwing during a water-polo game is

\footnotetext{
1 - Univ. Lille, Univ. Artois, Univ. Littoral Cote d'Opale, EA 7369 - URePSSS - Unité de Recherche Pluridisciplinaire Sport Santé Société, F-59000 Lille, France.
} 
overhead throwing (Bloomfield et al., 1990). Biomechanical analysis of overhead throwing has revealed that the shoulder is medially rotated and horizontally adducted by the anterior shoulder muscles (Feltner, 1986). When performing overhead activities such as throwing in waterpolo, the rotator muscles in the shoulder play a critical role in providing both mobility and stability to the glenohumeral joint (Boettcher et al., 2010). However, throwing velocity is multifactorial. In women, anthropometric characteristics such as the arm span or forearm girth, and lower body power have been identified as predictors of throwing velocity (Alcaraz et al., 2011; Martínez et al., 2015; McCluskey et al., 2010; Zinner et al., 2015). Nevertheless, the influence of shoulder rotator performance on throwing velocity has never been evaluated.

Analysis of women's water polo game revealed that water polo can be characterised as a high intensity intermittent sport (Tan et al., 2009a). Players perform approximately 54 high intensity activities per game, one every $38 \mathrm{~s}$ (Tan et al., 2009a). Elite players generally exhibit sprinting and endurance swimming abilities (Tan et al., 2009b). During swimming, the shoulder also moves into internal rotation, extension, and adduction at the glenohumeral joint during early pull-through. Internal and adduction strength have been reported to be greater in swimmers compared to the normal population (Batalha et al., 2013). However, the relationship between shoulder internal rotators and/or extensors performance and swimming velocity has not been evaluated. It would be of interest for coaches to choose adapted dry land strength training strategies to increase strength in the shoulder muscle groups involved in the generation of forces required for swimming.

Having considered that swimming and throwing have a common biomechanical basis in the use of the shoulder internal rotation and adductor muscles, the aim of the study was to evaluate the relationship between shoulder isokinetic variables and throwing velocity as well as swimming performance in female water-polo players. It was hypothesized that 1) peak torque of shoulder internal rotators would be a predictor of throwing velocity, and 2) peak torques of shoulder internal rotators and abductors would be predictors of $25 \mathrm{~m}$ swimming performance.

\section{Methods}

\section{Participants}

Fifteen female players of the French water-polo national team participated in this study (mean \pm SD: $22 \pm 2$ years; $68 \pm 9 \mathrm{~kg} ; 1.72 \pm$ $0.08 \mathrm{~m})$. The study was approved by the local Ethics Board and the athletes were informed of the benefits and risks of the investigation prior to signing an institutionally approved informed consent document to participate in the study. The protocol was conducted according to the Declaration of Helsinki.

Study design

Each player performed the following tests: (1) a throwing velocity test, (2) a $25 \mathrm{~m}$ swimming trial, (3) a $100 \mathrm{~m}$ swimming trial, (4) a $400 \mathrm{~m}$ swimming trial, and (5) an isokinetic evaluation. The players performed two tests per day separated by a minimum of $8 \mathrm{hr}$.

Assessment of throwing velocity

Throwing velocity was measured using a radar gun (SR3600, Sports Radar Ltd, Homosassa, USA), which operates using the Doppler effect. The radar was placed $5 \mathrm{~m}$ behind the goal post. Players completed a standardized warm-up comprised of $5 \mathrm{~min}$ of light-moderate swimming followed by $5 \mathrm{~min}$ of throwing with a progressive increase of intensity until maximal intensity was reached. The players performed 6 shots from the 5 $\mathrm{m}$ penalty line. A $30 \mathrm{~s}$ rest period elapsed between throws to minimize the effects of fatigue and reduce the risk of injury to the participants. The best shot was selected for further analysis.

\section{Assessment of swimming velocity}

After a standardized $10 \mathrm{~min}$ swimming warm-up, the players performed three tests of swimming capacity: a $25 \mathrm{~m}, 100 \mathrm{~m}$ and $400 \mathrm{~m}$ trial in an indoor $25 \mathrm{~m}$ swimming pool on three separate occasions. During the $100 \mathrm{~m}$ and $400 \mathrm{~m}$ trials, the players touched the wall after every 25 $\mathrm{m}$ lap. The time was recorded with a manual stopwatch (Casio, Japan) by three instructors and the measurement begun when the legs left the wall and stopped when the hand touched the wall. The mean value was selected for analysis. The start was given in water with a whistle blow.

\section{Assessment of isokinetic torque}

The measurements were performed using an isokinetic dynamometer (Con-Trex, Medimex, Sainte Foy les Lyon, France). Isokinetic assessment was performed in the dominant arm 
for internal rotators (IR) and external rotators (ER) of the shoulder joint with the players in the supine position with the arm abducted at $90^{\circ}$ in the frontal plane and the elbow flexed at $90^{\circ}$. The range of motion was standardized between $50^{\circ}$ of internal rotation and $70^{\circ}$ of external rotation as per Forthomme et al. (2013). Three conditions were tested: 1) 3 maximum concentric movements at an angular velocity of $\left.60^{\circ} \cdot \mathrm{s}^{-1}, 2\right) 3$ maximum concentric movements at an angular velocity of $240^{\circ} \cdot \mathrm{s}^{-1}$, 3) 3 maximum eccentric movements of the external rotator at an angular velocity of $60^{\circ} \cdot \mathrm{s}^{-1}$ with a passive movement of the internal rotator at an angular velocity of $60^{\circ} \cdot \mathrm{s}^{-1}$. Isokinetic assessment was performed in both arms for shoulder extensors (EXT) with extended elbows. The range of motion was standardized between $50^{\circ}$ of extension and $70^{\circ}$ of flexion. The flexion was performed passively at an angular velocity of $60^{\circ} \cdot \mathrm{s}^{-1}$. Two conditions were tested: 1) 3 maximum concentric movements at an angular velocity of $60^{\circ} \cdot \mathrm{s}^{-1}$, 2) 20 maximum concentric movements at an angular velocity of $240^{\circ} \cdot \mathrm{s}^{-1}$.

Isokinetic testing procedures enabled the measurement of absolute peak torque (PT; $\mathrm{N} \cdot \mathrm{m}$ ) and body mass relative to PT $\left(\mathrm{N} \cdot \mathrm{m} \cdot \mathrm{kg}^{-1}\right)$. The total work load was determined during the 20 repetition test and expressed relative to body mass $\left(\mathrm{J} \cdot \mathrm{kg}^{-1}\right)$. Agonist-antagonist ratios (ER/IR) were calculated using the same speed and contraction mode for the agonist and antagonist muscle groups (Forthomme et al., 2013). In addition to the usual "concentric" ratios, a mixed ratio (combining ER PT in the eccentric mode at $60^{\circ} \cdot \mathrm{s}^{-1}$ and IR PT in the concentric mode at $240^{\circ} \cdot \mathrm{s}^{-1}$ ) was designed to more specifically approximate the relationship between shoulder muscles during the throwing motion (Scoville et al., 1997).

\section{Statistical analysis}

Data are presented as means \pm SD. Statistical analyses were performed using Sigma Stat for Windows (version 3.0, SPSS Inc., Chicago, IL). After testing for normality and variance homogeneity, the relationships between isokinetic variables and swimming speed as well as throwing velocity were determined using Pearson correlation analysis. Variables significantly associated with throwing velocity and swimming speed were entered into the regression model as independent variables. Prior to calculating multiple regression models, the predictors (i.e. isokinetic variables) were checked for multicollinearity by calculating the variance inflation factor (VIF). The significance level was set at $p<0.05$.

\section{Results}

The mean throwing velocity was $15.3 \pm 0.8$ $\mathrm{m} \cdot \mathrm{s}^{-1}$. The mean swimming speeds were $1.76 \pm 0.1$ $\mathrm{m} \cdot \mathrm{s}^{-1}$ for the $25 \mathrm{~m}, 1.43 \pm 0.1 \mathrm{~m} \cdot \mathrm{s}^{-1}$ for the $100 \mathrm{~m}$ and $1.25 \pm 0.1 \mathrm{~m} \cdot \mathrm{s}^{-1}$ for the $400 \mathrm{~m}$ trial. Table 1 summarizes the mean values of isokinetic evaluations. No difference was observed between the dominant and non-dominant side during the shoulder extension evaluations.

All variables significantly associated with throwing velocity in bivariate analysis were entered into a multivariable regression model to determine the independent predictors of throwing velocity (Table 2). Peak torque of IR at Con 60 and Con 240 were closely correlated with each other in bivariate analysis and their concurrent inclusion in multiple regression analysis resulted in a VIF $>10$, indicating high multicollinearity. Accordingly, peak torques at each speed were separately entered into the regression model. The best model was obtained with concentric IR peak torque at $60^{\circ} \cdot \mathrm{s}^{-1}$ and eccentric ER peak torque at $60^{\circ} \cdot \mathrm{s}^{-1}\left(\mathrm{r}^{2}=0.52, p=0.012\right)$.

All variables significantly associated with $25 \mathrm{~m}, 100 \mathrm{~m}$ and $400 \mathrm{~m}$ swimming velocity in bivariate analysis were entered into a multivariable regression model to determine the independent predictors of the different swimming velocities (Table 3). Relative total work $\left(\mathrm{J} \cdot \mathrm{kg}^{-1}\right)$ and EXT peak torque at $60^{\circ} \cdot \mathrm{s}^{-1}$ remained the independent predictors of $25 \mathrm{~m}$ swimming velocity when the variables were included in the regression model $\left(\mathrm{r}^{2}=0.71, p=0.001\right)$. No correlation was observed between the isokinetic variables and $100 \mathrm{~m}$ swimming velocity. Relative total work $\left(\mathrm{J} \cdot \mathrm{kg}^{-1}\right)$ remained the only independent predictor of $400 \mathrm{~m}$ swimming velocity when the variables were included in the regression model $\left(\mathrm{r}^{2}=0.27, p=0.044\right)$.

\section{Discussion}

The aim of this study was to examine the relationship between isokinetic shoulder evaluations and throwing velocity as well as swimming performance in female water-polo players. 
Table 1

Isokinetic performances of dominant and non-dominant shoulders

\begin{tabular}{cccc}
\hline Variables & Angular Velocity $\left({ }^{\circ} \cdot \mathrm{s}^{-1}\right)$ & D Side & ND Side \\
\hline Peak Torque IR $(\mathrm{N} \cdot \mathrm{m})$ & Con 60 & $37.3 \pm 9.6$ & \\
& Con 240 & $31.9 \pm 5.9$ & \\
Peak Torque ER $(\mathrm{N} \cdot \mathrm{m})$ & Ecc 60 & $40.6 \pm 10.3$ & \\
Ratio ER/IR & Con 60 & $0.65 \pm 0.11$ & \\
& Con 240 & $0.66 \pm 0.08$ & \\
Mixed ratio ER/IR & Ecc $60 /$ Con 240 & $1.27 \pm 0.21$ & \\
Peak Torque EXT $(\mathrm{N} \cdot \mathrm{m})$ & Con 60 & $72.5 \pm 12$ & $72.0 \pm 9.5$ \\
Total work done $\left(\mathrm{J} \cdot \mathrm{kg}^{-1}\right)$ & Con 240 & $29.8 \pm 3.8$ & $29.0 \pm 3.6$ \\
\hline
\end{tabular}

Values are presented as mean \pm SD. D Side, Dominant Side; ND Side,

Non-dominant Side; Con $60=60^{\circ} \cdot \mathrm{s}^{-1}$, concentric mode; Con $240=240^{\circ} \cdot \mathrm{s}^{-1}$, concentric mode;

Ecc $60=60^{\circ} \cdot \mathrm{s}^{-1}$, eccentric mode. ER, external rotators, IR, Internal rotators, EXT, shoulder extensors.

Table 2

Correlations between throwing velocity and related variables in bivariate analysis

\begin{tabular}{ccc}
\hline & $\mathbf{r}$ & $p$ \\
\hline Peak Torque IR Con 60 & 0.692 & 0.004 \\
Peak Torque IR Con 240 & 0.649 & 0.009 \\
Peak Torque ER Ecc 60 & 0.681 & 0.005 \\
\hline
\end{tabular}

Con $60=60^{\circ} \cdot \mathrm{s}^{-1}$, concentric mode; Con $240=240^{\circ} \cdot \mathrm{s}^{-1}$, concentric mode;

Ecc $60=60^{\circ} \cdot \mathrm{s}^{-1}$, eccentric mode. ER, external rotators, IR, Internal rotators.

Table 3

Correlations between swimming velocities and related variables in bivariate analysis

\begin{tabular}{ccccccc}
\hline & \multicolumn{2}{c}{$\mathbf{2 5} \mathbf{~ m}$} & \multicolumn{2}{c}{$\mathbf{1 0 0} \mathbf{~ m}$} & \multicolumn{2}{c}{$400 \mathbf{~ m}$} \\
\hline & $\mathbf{r}$ & $\boldsymbol{p}$ & $\mathbf{r}$ & $p$ & $\mathbf{r}$ & $p$ \\
\hline Peak Torque IR Con 60 & -0.21 & 0.224 & -0.15 & 0.291 & 0.04 & 0.443 \\
Peak Torque IR Con 240 & -0.41 & 0.063 & -0.09 & 0.376 & 0.09 & 0.368 \\
Peak Torque ER Con 60 & -0.46 & 0.041 & -0.38 & 0.077 & -0.23 & 0.202 \\
$\begin{array}{c}\text { Peak Torque EXT (N.m) } \\
\quad \text { Con 60 }\end{array}$ & -0.63 & 0.006 & -0.34 & 0.109 & -0.20 & 0.234 \\
$\begin{array}{c}\text { Total work done }\left(\mathrm{J} \cdot \mathrm{kg}^{-1}\right) \\
\quad \text { Con 240 }\end{array}$ & -0.76 & 0.001 & -0.29 & 0.140 & -0.53 & 0.022 \\
\hline
\end{tabular}

Con $60=60^{\circ} \cdot \mathrm{s}^{-1}$, concentric mode; Con $240=240^{\circ} \cdot \mathrm{s}^{-1}$, concentric mode;

Ecc $60=60^{\circ} \cdot \mathrm{s}^{-1}$, eccentric mode. ER, external rotators, IR, Internal rotators,

EXT shoulder extensors. 
Results revealed that concentric peak torque of internal rotators and eccentric peak torque of external rotators were predictors of throwing velocity. Relative total work and peak torque of shoulder extensors were good predictors of $25 \mathrm{~m}$ swimming velocity.

The effectiveness of the shot depends, in part, on throwing velocity. The mean value of the maximal throwing velocity that was recorded in this study was $15.3 \pm 0.8 \mathrm{~m} \cdot \mathrm{s}^{-1}$. These values were similar to those reported previously (range: 13.9 to $16.1 \mathrm{~m} \cdot \mathrm{s}^{-1}$ ) (McCluskey et al., 2010).

A number of variables have been tested to determine their influence on throwing velocity. Previous studies showed that anthropometric characteristics influenced throwing velocity in female water polo players (McCluskey et al., 2010; Platanou and Botonis, 2010; Platanou and Varamenti, 2011). Specifically, body height, arm span and calf and upper arm girths were associated with throwing velocity. Moreover, the influence of lower limb power is or is not considered as a significant predictor of throwing velocity (Martínez et al., 2015; McCluskey et al., 2010; Platanou and Botonis 2010; Platanou and Varamenti, 2011). In our study, we focused on the shoulder torque influence on throwing velocity. Similarly to the study of Platanou and Varamenti (2011), we found a correlation between internal rotators and throwing velocity. This is consistent with the fact that muscular performance is an essential requirement to achieve high throwing velocity (Pedegana et al., 1982) and that the production of the maximal torque at the rotator muscles of the shoulder zone has a high correlation with throwing velocity (Bloomfield et al., 1990).

In our study, we evaluated external rotators in the eccentric mode based on the fact that during throwing, there is a complementary action of concentric and eccentric contractions. During overarm throwing, there is an antagonist activity involved in deceleration following the release of the ball (Hirashima et al., 2002). The eccentric contraction of external rotators plays a key role and acts as a brake during the final deceleration of the upper limb, thereby limiting the pronounced increase in distraction force (Sirota et al., 1997). Taken together the results suggest that concentric peak torque of internal rotators and eccentric peak torque of external rotators should be developed together to maximize the throwing velocity increase.

Several biochemical studies regarding competitive swimming have documented that propulsive forces responsible for total body displacement are mainly produced by the upper limbs, through arm adduction and shoulder internal rotation (Olivier et al., 2008; Yanai and Hay, 2000). A common criticism of isokinetic testing is the lack of agreement between the test and performance speed. In our study, we chose a speed of $240^{\circ} \cdot \mathrm{s}^{-1}$ which is similar to pull-through phase duration reported previously (Bak and Magnusson, 1997). The present study evaluated peak torques of both internal rotators and arm adductors. We did not find a relationship between swimming velocity and peak torque of shoulder rotators. However, we observed that both shoulder extensors peak torque and total work remained independent predictors of $25 \mathrm{~m}$ swimming velocity, but not $100 \mathrm{~m}$ and $400 \mathrm{~m}$ swimming velocities. We could hypothesize that the absence of the relationship between peak torque and $100 \mathrm{~m}$ and $400 \mathrm{~m}$ swimming velocities could be explained by muscle fatigue that occurs during evaluations leading to lower muscle peak torque. Accordingly, a previous study showed that muscle fatigue occurred during short duration and high speed swims suggesting that muscle peak torque and muscle endurance were distinct characteristics (Bassan et al., 2015). Future studies should evaluate if isokinetic muscle endurance evaluations reflect enduranceswimming performance. All together, these results suggest that maximal and short duration isokinetic evaluations only reflect swimming velocities during short duration.

This study showed that isokinetic evaluations reflected throwing velocity as well as swimming velocity in elite female water polo players. This has significant implication for training practices and evaluations of this population. Firstly, for training strategies, it is recommended to develop eccentric strength of shoulder external rotators to enhance throwing velocity of the players. Moreover, coaches should use training programs to develop shoulder adductor force in order to enhance sprint swimming performance. Secondly, the use of isokinetic testing has significant implications for team selection, evaluation and training strategies. 
Specifically, isokinetic evaluations may help coaches identify whether they should focus on muscle strength development or throwing technique.

The present study had some limitations which require further discussion. The swimming evaluations were performed with the front crawl with the head under the water technique. Kinematic differences have been previously observed between different front crawl techniques in young female players (Zamparo and Falco, 2010). However, no swimming velocity differences were reported (De Jesus et al., 2012). Since we compared swimming velocity and isokinetic evaluation, we hypothesized that the use of the front crawl with the head under the water technique would reflect the performance with the use of the front crawl with the head above the water technique. Another limitation was the $25 \mathrm{~m}$ distance which did not reflect accurately the elite female water-polo sprint distance (Tan et al., 2009a). However, the comparison of $15 \mathrm{~m}$ and $25 \mathrm{~m}$ sprint tests showed a high correlation level (Kontic et al., 2017). We assumed that higher correlations with isokinetic variables would be observed in a $15 \mathrm{~m}$ swimming test.

\section{Conclusions}

Isokinetic shoulder evaluations correlated significantly with swimming performance and throwing velocity in female water-polo players. We observed that both concentric and eccentric peak torques were influenced by throwing velocity. Future studies should examine the influence of chronic training on shoulder rotators and throwing velocity.

\section{References}

Alcaraz PE, Abraldes JA, Ferragut C, Rodriguez N, Argudo FM, Vila H. Throwing velocities, anthropometric characteristics, and efficacy indices of women's European water polo subchampions. J Strength Cond Res, 2011; 25(11): 3051-3058

Bak K, Magnusson SP. Shoulder Strength and Range of Motion in Symptomatic and Pain-Free Elite Swimmers. Am J Sports Med, 1997; 25(4): 454-459

Bassan NM, César T, Denadai BS. Relationship Between Fatigue and Changes in Swim Technique During an Exhaustive Swim Exercise. Int J Sports Physiol Perform, 2015; 11(1): 33-39

Batalha NM, Raimundo AM, Tomas-Carus P, Barbosa TM, Silva AJ. Shoulder Rotator Cuff Balance, Strength, and Endurance in Young Swimmers During a Competitive Season. J Strength Cond Res, 2013; 27(9): 2562-2568

Bloomfield J, Blanksby BA, Ackland TR. The influence of Strength Training on Guerhead Threading Velocity cf Elite Water Polo Players. Aust J Sci Med Sports, 1990; 22(3): 63-67

Boettcher CE, Cathers I, Ginn KA. The role of shoulder muscles is task specific. J Sci Med Sport, 2010; 13(6): 651-656

Botonis PG, Toubekis AG, Platanou TI. Physical Performance During Water-Polo Matches: The Effect of the Players' Competitive Level. J Hum Kinet, 2016; 54(1):135-142

De Jesus K, Figueiredo P, De Jesus K, Pereira F, Vilas-Boas JP, Machado L, Fernandes RJ. Kinematic analysis of three water polo front crawl styles. J Sports Sci, 2012; 30(7): 715-723

Feltner M. Dynamics of the shoulder and elbow joints of the throwing arm during a baseball pitch. J Appl Biomech, 1986; 2(4): 235-259

Forthomme B, Wieczorek V, Frisch A, Crielaard JM, Croisier JL. Shoulder pain among high-level volleyball players and preseason features. Med Sci Sports Exerc, 2013; 45(10): 1852-1860

Hirashima M, Kadota H, Sakurai S, Kudo K, Ohtsuki T. Sequential muscle activity and its functional role in the upper extremity and trunk during overarm throwing. J Sports Sci, 2002; 20(4): 301-310

Kontic D, Zenic N, Uljevic O, Sekulic D, Lesnik B. Evidencing the association between swimming capacities and performance indicators in water polo: a multiple regression study. J Sports Med Phys Fitness, 57(6): 734-743

Martínez JG, Vila MH, Ferragut C, Noguera MM, Abraldes JA, Rodrigues N, Freeston J, Alcaraz PE. 
Position-specific anthropometry and throwing velocity of elite female water polo players. J Strength Cond Res, 2015; 29(2): 472-477

McCluskey L, Lynskey S, Leung CK, Woodhouse D, Briffa K, Hopper D. Throwing velocity and jump height in female water polo players: performance predictors. J Sci Med Sport, 2010; 13(2): 236-240

Olivier N, Quintin G, Rogez J. The high level swimmer articular shoulder complex. Ann Readapt Med Phys, 2008; 51(5): 342-347

Ordóñez EG, Pérez M, González CT. Performance Assessment in Water Polo Using Compositional Data Analysis. J Hum Kinet, 2016; 54: 143-151

Pedegana LR, Elsner RC, Roberts D, Lang J, Farewell V. The relationship of upper extremity strength to throwing speed. Am J Sports Med, 1982; 10(6): 352-354

Platanou T, Botonis P. Biomechanics and Medicine in Swimming XI, Oslo: P.-L. Kjendlie, R.K. Stallman, J. Cabri, 77-78; 2010

Platanou T, Varamenti E. Relationships between anthropometric and physiological characteristics with throwing velocity and on water jump of female water polo players. J Sports Med Phys Fitness, 2011; 51(2): 185-193

Scoville CR, Arciero RA, Taylor DC, Stoneman PD. End range eccentric antagonist/concentric agonist strength ratios: a new perspective in shoulder strength assessment. J Orthop Sports Phys Ther, 1997; 25(3): 203-207

Sirota SC, Malanga GA, Eischen JJ, Laskowski ER. An Eccentric- and Concentric-Strength Profile of Shoulder External and internal Rotator Muscles in Professional Baseball Pitchers. Am J Sports Med, 1997; 25(1): 59-64

Smith DHK. Applied Physiology of Water Polo. Sports Med, 1998; 26(5): 317-334

Tan F, Polglaze T, Dawson B. Activity profiles and physical demands of elite women's water polo match play. J Sports Sci, 2009a; 27(10): 1095-1104

Tan FHY, Polglaze T, Dawson B, Cox G. Anthropometric and fitness characteristics of elite Australian female water polo players. J Strength Cond Res, 2009b; 23(5): 1530-1536

Tucher G, de Souza Castro FA, da Silva AJRM, Garrido ND. The Functional Fest for Agility Performance is a Reliable Quick Decision-Making Test for Skilled Water Polo Players. J Hum Kinet, 2015; 46: 157-165

Vila MH, Abraldes JA, Rodríguez N, Ferragut C. Tactical and shooting variables that determine win or loss in top-Level in water polo: analysis by phases of the game. Int J Perform Anal Sport, 2011; 12: 373-384

Yanai T, Hay JG. Shoulder impingement in front-crawl swimming: II. Analysis of stroking technique. Med Sci Sports Exerc, 2000; 32(1): 30-40

Zamparo P, Falco S. Biomechanics and Medicine in Swimming XI, Oslo: P.-L. Kjendlie, R.K. Stallman, J. Cabri, $187-189 ; 2010$

Zinner C, Sperlich B, Krueger M, Focke T, Reed J, Mester J. Strength, Endurance, Throwing Velocity and inWater Jump Performance of Elite German Water Polo Players. J Hum Kinet, 2015; 45: 149-156

\section{Corresponding author:}

Frédéric N. Daussin, Ph.D.

Eurasport, 413 avenue Eugène Avinée, 59120 Loos, France;

Phone: +33 (0)3.74.00.82.15.;

Fax: +33 (0)3.20.88.73.63.

E-mail: frederic.daussin@univ-lille.fr 